\title{
A Study of Clinical Predictors Associated With Intrinsic Sphincter Deficiency in Women With Stress Urinary Incontinence
}

\author{
Kyung Kgi Park, Sung Dae Kim, Jung-Sik Huh, Young-Joo Kim \\ Department of Urology, Jeju National University School of Medicine, Jeju, Korea
}

Purpose: Recently, intrinsic sphincter deficiency (ISD) has been identified as one important factor in the outcome of stress urinary incontinence (SUI) related surgery. Clinical factors that can predict ISD are uncommon. The aim of this study was to determine predictive clinical factors for ISD in female patients with SUI.

Methods: The patients were classified into 3 groups according to the value of Valsalva leak point pressure (VLPP) $>90 \mathrm{~cm}$ $\mathrm{H}_{2} \mathrm{O}$ (anatomical incontinence, $\mathrm{AI}$ ), between 61 and $90 \mathrm{~cm} \mathrm{H} \mathrm{H}_{2} \mathrm{O}$ (equivocal, $\mathrm{EV}$ ), and $<60 \mathrm{~cm} \mathrm{H}_{2} \mathrm{O}$ (ISD). All groups underwent a full examination, history evaluation, physical examination, uroflowmetry, and complete urodynamic study. Univariate analysis was performed by chi-square or t-test for categorical variables, respectively. A multivariate study was performed by Pearson correlation analysis in order to get clinical predictors of VLPP $<60 \mathrm{~cm} \mathrm{H}_{2} \mathrm{O}$. Statistical significance was set at $\mathrm{P}<0.05$. Results: There were 3 groups with a total of 189 patients: 56 patients (AI, 29.7\%), 64 patients (EV, 33.8\%), and 69 patients (ISD, $36.5 \%)$. The univariate analysis revealed a significant difference associated with maximal urethral closing pressure $(\mathrm{P}=0.03)$ and Stamey classification $(\mathrm{P}=0.006)$ between ISD and AI. The more severe the urinary symptom grade, the higher the frequency of ISD. However, the multivariate analysis showed the independent predictor of ISD is only present in grades II and III symptoms in the Stamey classification $(\mathrm{P}=0.001)$.

Conclusions: It was found that the more severe the symptoms of urinary incontinence, the higher the possibility of ISD. In other words, the degree of urinary incontinence was found to be one relevant clinical factor in predicting ISD. This finding may help in evaluating and identifying the appropriate surgical technique for EV. Currently, absolute cutoff value to diagnose ISD has not yet been determined. More research is needed to identify clinical factors that can predict ISD.

Keywords: Urinary incontinence, Stress; Urodynamics; Urethra

- Research Ethics: This study was approved by the Institutional Review Board of Jeju National University (approval number: JEJUNUH 2016-07013).

- Conflict of Interest: No potential conflict of interest relevant to this article was reported.

\section{INTRODUCTION}

Female stress urinary incontinence (SUI) is divided into 3 groups (anatomical incontinence [AI], intrinsic sphincter deficiency [ISD], and equivocal [EV]). In ISD, regardless of the anatomical location of the urethra, urinary incontinence occurs in the dysfunction of the urethral sphincter itself. A high failure rate of an- ti-incontinence surgeries has been reported without an accurate diagnosis of ISD. However, diagnosis of ISD does not have definite criteria yet. Recently, Valsalva leak point pressure (VLPP) measurement has been used as a reliable and universal method for SUI. ISD has been diagnosed below $60 \mathrm{~cm} \mathrm{H}_{2} \mathrm{O}$; however, VLPP has not been standardized yet. ISD is more likely to occur in patients with clinical findings, such as age, hormone deficien-

Corresponding author: Young-Joo Kim (D) https://orcid.org/0000-0001-5580-4338 Department of Urology, Jeju National University School of Medicine 102, Jeju Deahak-ro, Jeju 63243, Korea

E-mail: kurology@jejunu.ac.kr / Tel: +82-64-717-1760 / Fax: +82-64-717-1131

Submitted: August 26, 2016 / Accepted after revision: November 10, 2016 
cy, urinary incontinence surgery, damage to the pelvis and pelvic radiation therapy. Therefore, various assessments such as premedical history, physical examination, image studies and urodynamic studies such as VLPP have been used for an accurate diagnosis of ISD. Clinical factors that can predict ISD are uncommon, so this study attempted to investigate the predictors of ISD.

\section{MATERIALS AND METHODS}

The study consisted of 189 patients who had been diagnosed with SUI from January 2005 to December 2015. The exclusion criteria of patients were (1) detrusor instability in urodynamics, (2) neurogenic bladder, (3) urge urinary incontinence, (4) mixed urinary incontinence, and (5) overactive bladder.

Mean age was $52.49 \pm 10.61$ years. Patients were classified into 3 groups according to the value of VLPP $>90 \mathrm{~cm} \mathrm{H}_{2} \mathrm{O}$ (AI, 29.7\%), between 61 and $90 \mathrm{~cm} \mathrm{H}_{2} \mathrm{O}(\mathrm{EV}, 33.8 \%)$, and $<60 \mathrm{~cm}$ $\mathrm{H}_{2} \mathrm{O}$ (ISD, 36.5\%) [1]. All groups underwent a full examination, evaluation of history, physical examination, uroflowmetry, and urodynamic study. The associated clinical factors were evaluated, including age, body weight, urinary incontinence symptom grade, overactive symptoms (frequency, urgency, urge incontinence), urinary anti-incontinence surgery, number of pregnancies and childbirths, and pelvic cavity therapy. The degrees of urinary incontinence were divided into 3 stages according to the Stamey classification. Stamey grade I is defined as urinary incontinence that occurs with general increase in abdominal pressure (coughing, sneezing, jump rope, etc.). Grade II is caused by a mild increase in abdominal pressure (sitting, standing, walking, etc.). Regardless of the change in one's position, grade III is defined as urinary incontinence with no relation to physical activity. The univariate analysis was performed by chisquare or t-test for categorical variables and contiguous variables, respectively. The multivariate study was performed by Pearson correlation analysis in order to get clinical predictors of VLPP $<60 \mathrm{~cm} \mathrm{H}_{2} \mathrm{O}$. Statistical significance was set at $\mathrm{P}<0.05$.

\section{RESULTS}

A total of 189 patients comprised 3 groups: 56 patients (AI,

Table 1. Patient characteristics $(\mathrm{n}=189)$

\begin{tabular}{ll}
\hline Characteristic & Mean \pm SD \\
\hline Age $(\mathrm{yr})$ & $52.49 \pm 10.61$ \\
Body mass index $\left(\mathrm{kg} / \mathrm{m}^{2}\right)$ & $25.48 \pm 3.17$ \\
Weight $(\mathrm{kg})$ & $69.77 \pm 3.17$ \\
Bladder capacity $(\mathrm{mL})$ & $338.9 \pm 112.1$ \\
Pdetmax $\left(\mathrm{cm} \mathrm{H}_{2} \mathrm{O}\right)$ & $39.12 \pm 1.29$ \\
Residual urine $(\mathrm{mL})$ & $41.23 \pm 33.79$ \\
Qmax $(\mathrm{mL} / \mathrm{sec})$ & $19.19 \pm 8.05$
\end{tabular}

SD, standard deviation; Pdetmax, maximum detrusor pressure; Qmax, maximal flow rate.

Table 2. Comparison of clinical parameters between intrinsic sphincter deficiency (ISD) and anatomical incontinence (AI)

\begin{tabular}{lccc}
\hline Parameter & ISD $(\mathrm{n}=69)$ & AI $(\mathrm{n}=56)$ & P-value \\
\hline Age $(\mathrm{yr})$ & $54.7 \pm 10.8$ & $52.7 \pm 9.5$ & 0.57 \\
Weight $(\mathrm{kg})$ & $60.2 \pm 7.9$ & $61.1 \pm 9.2$ & 0.18 \\
Body mass index $\left(\mathrm{kg} / \mathrm{m}^{2}\right)$ & $25.0 \pm 2.6$ & $25.3 \pm 3.3$ & 0.86 \\
Pregnancy, median & 3.32 & 2.8 & 0.64 \\
Delivery, median & 2.28 & 2.23 & 0.45 \\
Menopausal & $22(31.9)$ & $30(53.6)$ & 0.96 \\
Stamey grade & & & $0.006^{*}$ \\
I & $30(43.5)$ & $53(94.6)$ & \\
II & $28(40.6)$ & $3(5.4)$ & 0.072 \\
III & $11(15.9)$ & $32(57.1)$ & 0.85 \\
Frequency & $30(43.5)$ & $44(78.6)$ & \\
Urgency & $36(52.2)$ & $32(57.1)$ & 0.73 \\
Urge incontinence & $21(30.4)$ & $3(5.4)$ & 0.24 \\
Anti-incontinence & $6(8.7)$ & $6(10.7)$ & 0.92 \\
Hysterectomy & $3(4.35)$ & & \\
\hline
\end{tabular}

Values are presented as mean \pm standard deviation or number (\%) unless otherwise indicated. ${ }^{*} \mathrm{P}<0.05$, statistically significant difference. 
Table 3. Comparison of urodynamic parameters between intrinsic sphincter deficiency (ISD) and anatomical incontinence (AI)

\begin{tabular}{lccc}
\hline Parameter & ISD & AI & P-value \\
\hline Capacity $(\mathrm{mL})$ & $343.4 \pm 98.4$ & $310 \pm 126.6$ & 0.22 \\
MUCP $\left(\mathrm{cm} \mathrm{H}_{2} \mathrm{O}\right)$ & $29.5 \pm 14.4$ & $34.9 \pm 9.6$ & $0.03^{*}$ \\
Pdetmax $\left(\mathrm{cm} \mathrm{H}_{2} \mathrm{O}\right)$ & $32.3 \pm 8.8$ & $43.1 \pm 20.7$ & 0.15 \\
Qmax $(\mathrm{mL} / \mathrm{sec})$ & $17.4 \pm 7.3$ & $17.9 \pm 8.3$ & 0.93 \\
Residual urine $(\mathrm{mL})$ & $31 \pm 4.8$ & $11.6 \pm 7.1$ & 0.39 \\
\hline
\end{tabular}

Values are presented as mean \pm standard deviation.

MCUP, maximal cuff urethral pressure; Pdetmax, maximum detrusor pressure; Qmax, maximal flow rate.

${ }^{*} \mathrm{P}<0.05$, statistically significant difference.

Table 4. Correlation coefficients between Valsalva leak point pressure and clinical parameters associated with stress urinary incontinence (SUI) parameters

\begin{tabular}{lcc}
\hline $\begin{array}{l}\text { Parameter associated } \\
\text { with SUI }\end{array}$ & $\begin{array}{c}\text { Correlation } \\
\text { coefficients }(\mathrm{r})\end{array}$ & P-value \\
\hline Age & -0.125 & 0.293 \\
Body mass index & 0.054 & 0.627 \\
Stamey grade & -0.540 & $0.001^{*}$ \\
MUCP & -0.224 & 0.442 \\
Residual urine & 0.090 & 0.506 \\
Qmax & 0.148 & 0.213 \\
\hline
\end{tabular}

MCUP, maximal cuff urethral pressure; Qmax, maximal flow rate. ${ }^{*} \mathrm{P}<0.05$, statistically significant difference.

29.7\%), 64 patients (EV, 33.8\%), and 69 patients (ISD, 36.5\%). The average age was $52.49 \pm 10.61$ and body mass index (BMI) was $25.48 \pm 3.17 \mathrm{~kg} / \mathrm{m}^{2}$. Urodynamic parameters consisted of such characters as bladder capacity $(338.9 \pm 112.1 \mathrm{~mL})$, detrusor pressure (Pdet) $\left(39.12 \pm 1.29 \mathrm{~cm} \mathrm{H}_{2} \mathrm{O}\right)$, and maximal flow rate (Qmax) (19.19 $\pm 8.05 \mathrm{~mL} / \mathrm{sec})$ (Table 1$)$. No significant difference between AI and ISD was shown with age, weight, BMI, pregnancy, delivery, menopausal, urinary frequency, urgency, urge incontinence, anti-incontinence surgery, or previous hysterectomy. The differences between ISD and AI in response to Stamey symptom grade were confirmed $(\mathrm{P}=0.006)$ (Table 2$)$. In urodynamic parameters, total bladder capacity, Pdet, Qmax, and residual urine did not show a significant difference between AI and ISD, while maximal urethral closure pressure (MUCP) showed a significant difference between AI and ISD $(\mathrm{P}=0.03)$ (Table 3$)$. In the ISD group, 30 patients were considered grade I (43.5\%), 28 were grade II (40.6\%), and 11 were grade III (15.9\%). In the AI group, 53 patients were grade I (94.6\%), 3 were grade II (5.4\%) and none were considered grade III. A negative statistical correlation $(\mathrm{r}=-0.540, \mathrm{P}=0.001)$ was shown when com- paring VLPP to Stamey grade (Table 4); in other words, the higher the Stamey grade, the lower the VLPP. Therefore, only the symptom grade of urinary incontinence in the clinical factors showed a significant difference between AI and ISD. The more severe the urinary symptom grade, the higher the frequency of ISD.

\section{DISCUSSION}

The proportion of patients with ISD among those with SUI is small. However, a high failure rate of anti-incontinence surgeries has been reported without an accurate diagnosis of ISD. AI occurs because abdominal pressure is transmitted only to the bladder and not the urethra and bladder neck. However, ISD is caused by internal sphincter weakening or failure of urethral mucosal coaptation, regardless of the urethral hypermobility. From this viewpoint, it is possible that different results of the anti-incontinent sling surgery occur between AI and ISD. Therefore, differential diagnosis of ISD is important before surgery.

In Nitti and Combs [2], EV patients had partially included symptoms of ISD. Traditionally, selection of anti-incontinence surgery of EV was applied according as EV has symptoms of ISD or AI because criteria for increasing a successful cure rate of EV was not known. Determining how to treat the EV patients with criteria such as ISD or AI will have a major impact on the success rate of treatment. It has been reported that most instances of SUI have symptoms of ISD [3]. ISD was identified in $76 \%$ of type III form, and AI almost always appears in the form of type II incontinence [4]. Anti-incontinence sling operations in SUI patients with severe symptoms or ISD have demonstrated poor results in long-term follow-up [5].

The higher the incontinence symptom grade, the lower the VLPP [2]. Similarly, in the present study, grade I was $23.25 \%$, 
grade II was $57.14 \%$ and grade III was $100 \%$ in the proportion of ISD in the whole Stamey grades, showing the more severe the symptoms, the higher the proportion of ISD. According to a previous study, patient age of over 50 was a clinical factor that can predict ISD [6]. However, in this study, no statistical significance was found.

Although it has been reported that the operative success rate of obese patients (BMI $>30 \mathrm{~kg} / \mathrm{m}^{2}$ ) was low [7], we found no statistical relation. According to McGuire [8], it was reported that $75 \%$ of total patients who underwent urinary incontinence surgery more than once had ISD. In this case, of the 14 patients who had urinary incontinence surgery more than once, the incidence of ISD (9 patients) was higher than AI (5 patients). However, no correlation was found.

Labor and delivery is known as a major risk factor for SUI. However, fetal body weight, the length and direction of the birth and episiotomy, and the degree of muscle damage to the pelvis all may differ. There are still debates on relevance between the obstetric risk factors and urinary incontinence. Sul$\tan$ has reported a high correlation between VLPP and MUCP [9], but Swift has reported no correlation between VLPP and MUCP with the exception the case of VLPP less than or equal to $45 \mathrm{~cm} \mathrm{H} \mathrm{H}_{2} \mathrm{O}$ [10]. According to the univariate analysis of this study, there was a statistical correlation between ISD and AI, but the multivariate analysis did not show a significant correlation between the VLPP and MUCP. In the past, the differential diagnosis of ISD and AI was based on the subjective experience of the operator, so it was difficult to find objective diagnostic criteria. Even more, in EV (VLPP, 60-91 cm $\mathrm{H}_{2} \mathrm{O}$ ), diagnostic value is not clear, so it was difficult to decide the proper treatment. Due to this trend, classification of AI and ISD might be necessary. If we cannot be excluded the elements of ISD in EV, sling surgery is inappropriate, there is a possibility of relapse after sling surgery. Therefore, it is very important for the success of the surgery to investigate the risk factors associated with ISD in SUI.
The specific factors associated with the pathophysiology of urinary incontinence have not yet been clearly investigated. Therefore, well-designed prospective studies including several clinical factors associated with SUI, including ISD, must be examined.

\section{REFERENCES}

1. Haab F, Zimmern PE, Leach GE. Female stress urinary incontinence due to intrinsic sphincteric deficiency: recognition and management. J Urol 1996;156:3-17.

2. Nitti VW, Combs AJ. Correlation of Valsalva leak point pressure with subjective degree of stress urinary incontinence in women. J Urol 1996;155:281-5.

3. Wahle GR, Young GP, Raz S. Vaginal surgery for stress urinary incontinence. Urology 1994;43:416-9.

4. McGuire EJ, Fitzpatrick CC, Wan J, Bloom D, Sanvordenker J, Ritchey M, et al. Clinical assessment of urethral sphincter function. J Urol 1993;150:1452-4.

5. Chaikin DC, Rosenthal J, Blaivas JG. Pubovaginal fascial sling for all types of stress urinary incontinence: long-term analysis. J Urol 1998;160:1312-6.

6. Horbach NS, Ostergard DR. Predicting intrinsic urethral sphincter dysfunction in women with stress urinary incontinence. Obstet Gynecol 1994;84:188-92.

7. Burgio KL, Matthews KA, Engel BT. Prevalence, incidence and correlates of urinary incontinence in healthy, middle-aged women. J Urol 1991;146:1255-9.

8. McGuire EJ. Urodynamic findings in patients after failure of stress incontinence operations. Prog Clin Biol Res 1981;78:351-60.

9. Sultana CJ. Urethral closure pressure and leak-point pressure in incontinent women. Obstet Gynecol 1995;86:839-42.

10. Swift SE, Ostergard DR. A comparison of stress leak-point pressure and maximal urethral closure pressure in patients with genuine stress incontinence. Obstet Gynecol 1995;85(5 Pt 1):704-8. 